\title{
The Influence of Parental Attachment on School Life Adjustment in Early Adolescence: The Mediating Effect of Internet Use Type
}

\author{
Kim, Seung Ryeol', Song, Jin Yeong ${ }^{2}$ \\ Department of Public Adminstration, Sungkyul University, Anyang, Korea ${ }^{1}$ \\ Department of Social Welfare, Sungkyul University, Anyang, Korea ${ }^{2}$ \\ 초기 청소년의 부모애착이 학교생활적응에 미치는 영향:
인터넷사용유형의 매개효과를 중심으로
}

김승렬 ${ }^{1}$ 송진영 ${ }^{2}$

성결대학교 행정학부 ${ }^{1}$, 성결대학교 사회복지학부 ${ }^{2}$

Objective: The purpose of this study was to examine the mediating effect of internet use type on the relationship between parental attachment and school life adjustment.

Methods: For this study, data were drawn from 4th wave panel data of Korea Children and Youth Panel Survey. 1,537 1st graders of middle school were used for analysis.

Results: The results of this study were summarized as follows. First, adolescents' parental attachment positively influenced school life adjustment. Second, study oriented internet use positively influenced school life adjustment. However, entertainment oriented internet use negatively influenced school life adjustment, and relation oriented internet use did not influence school life adjustment. Third, study and entertainment oriented internet use mediated parental attachment and school life adjustment. However, relation oriented internet use did not mediate parental attachment and school life adjustment.

Conclusion: The discovery that study oriented internet is a factor that can improve school life adjustment carries a significant meaning. Based on the results, some implications are discussed to improve school life adjustment in early adolescence.

Keywords: Parental attachment, School life adjustment, Internet use type, Early adolescence.$$
\text { 서론 }
$$

청소년기는 아동기에서 성인기로 넘어가는 시기로 신체적 발 달 뿐 아니라 심리적, 사회적으로 가장 많은 변화를 겪는 시기 이다. 또한 청소년기는 자아정체성을 찾아가는 시기이기 때문 에 청소년들이 경험하는 규범적 사건들 뿐 아니라 청소년이 성장하고 있는 환경으로 인한 사건들은 청소년시기에 결정적

Corresponding Author: Song, Jin Yeong, Department of Social Welfare, Sungkyul University, 53, Sungkyul Dea-Ro, Manan-Gu, Anyang-si, Gyeonggi-Do, Korea, 14097

E-mail: jysong4@daum.net
\end{abstract}

영향을 준다(Crockett \& Crouter, 1995). 이 중 학교는 청소년이 가장 많은 시간을 보내는 곳으로, 개인적, 사회적으로 잘 적응 하여 자기 능력을 충분히 발휘하여 보다 행복하고 원만한 생 활을 할 수 있도록 해주는 가장 중요한 환경이다(Moon, 2002). 특히 변화하는 사회적 환경 속에서 바르게 적응할 수 있는 힘 을 길러 나가는데 중요한 역할을 의도적으로 행하는 기관이 학교라는 점에서 청소년들이 학교생활에 적응하느냐, 적응하

CThe Korean Association of Child Studies

This is an Open Access article distributed under the terms of the Creative Commons Attribution Non-Commercial License (http:// creativecommons.org/licenses/by-nc/4.0) which permits unrestricted noncommercial use, distribution, and reproduction in any medium, provided the original work is properly cited. 
지 못하느냐의 문제는 그들이 성장하여 사회의 한 구성원으로 서 올바르게 생활해 나갈 수 있는지 여부를 결정하는 중요한 기준이 된다(Kim \& Ju, 2010).

하지만, 청소년들은 하루일과 중 가장 오랜 시간을 학교에 서 지내게 되면서 학교생활의 규칙과 또래 및 교사관계에서 비롯된 사회적 과제 등으로 인해 심리적 부담을 받을 수 있다. 또한 우리나라의 청소년들은 초등학교에서부터 입시교육에 억압되어 정상적인 심리적, 정서적, 사회적 발달이 저해되고 있으며, 미래에 대한 희망을 갖지 못하고 불안감과 소외감 등 의 심리적 문제와 함께 방황과 일탈에 쉽게 노출되고, 이는 결 국 학교생활부적응으로 이어질 수 있다(Sung et al., 2009).

청소년들의 학교생활부적응은 학교중퇴로 이어질 수 있고, 이는 향후 사회적, 학문적 지식과 기술을 습득하는데 걸림돌 이 되어, 결과적으로 성인이 되었을 때 직장과 가정에서의 역 할을 성공적으로 수행하는데 어려움을 겪을 수 있다(Richman, Bowen, \& Woolley, 2004). 또한 Park과 Moon (2006)은 우리나 라 상당수의 청소년들이 학교생활부적응의 문제로 학교를 중 단하는 사례가 늘고 있으며, 이러한 학교생활부적응은 심리 적, 정서적인 문제와 폭력, 무단결석, 가출, 약물남용, 비행 등 의 행동 문제로 이어져 심각한 청소년 문제의 원인이 될 수 있 기 때문에 조기에 발견하여 예방하는 것이 매우 중요하다고 하였다. 따라서 청소년의 적응행동을 이해하고 증진시키기 위 해서는 청소년들에게 중요한 생활환경인 학교생활에서의 적 응에 관한 실증적인 연구의 필요성이 강조된다.

학교생활적응이란 학생의 모든 행동이 학교 환경과의 상호 작용에서 잘 조화되고 성공적인 관계를 형성시킴으로써 동료 와 교사 등 의미 있는 타인들과 원만한 인간관계를 유지해 가 며, 학교수업에 적응하고 학교규범에 순응하면서 독립된 한 개인으로서 역할을 수행해 가는 것을 의미한다(Moon, 2002). $\mathrm{Khu}$ (2007)는 학교생활적응을 학습자가 학교상황에서 일어 나는 여러 가지 상황에 대처하는 일련의 어떤 노력으로서, 학 습자 자신의 요구를 학교 내의 현실적 가능성에 대처하려고 하는 학습자의 시도라고 정의하였으며, 학교생활적응을 잘 하는 학생들은 학교에 대한 감정이나 자신감 그리고 동기가 긍정적이어서 대인관계가 원만하고 그들의 행동특성도 바람 직하게 형성되어 학교와 사회발전에 큰 도움을 준다고 하였 다. 또한 학교생활적응을 사회심리적 측면에서 연구한 Ladd, Kochenderfer, 그리고 Coleman (1996)은 학교생활적응을 개인 이 학교환경에 지각과 감정, 그리고 관심을 가지고 참여하며, 편안해하고 학교생활을 성공적으로 수행할 수 있는 정도라고 하였다.
이에 청소년의 학교생활적응을 높이기 위한 연구들이 보고 되고 있는데, 이 중 부모와의 애착관계는 청소년의 학교생활 적응과 매우 밀접한 관련이 있는 요인으로 밝혀지고 있다. 애 착의 초기 연구는 대부분 영유아기가 주를 이루었으며, 유아 기 이후의 연구들은 제한적이었다. 청소년기에는 이러한 초기 애착이 더욱 확고해지거나 수정, 변형된다. 또한 청소년기는 부모로부터 분리-개별화 과정이 이루어지고 가족 외의 관계 가 발달하면서, 이 시기의 애착은 유아기의 애착과는 다른 특 성을 지닌다(Bretherton, 1999).

청소년기 특히 초기 청소년에 해당하는 중학교 1학년의 경 우 2차 성징에 의한 생물학적 변화 뿐 아니라 사회적 관계변화 도 경험하는 시기이다. 즉, 학교생활 시간이 늘어나면서 가족 내 부모 중심의 애착관계가 학교 내 친구 중심의 애착관계로 확장된다, 이로 인해 또래의 영향력이 커지면서 부모의 영향 으로부터 벗어나고 싶은 욕구는 커지지만, 그들은 여전히 부 모에게 의존하고 있는 양가적 행동을 보이며, 부모애착이 청 소년의 인지, 정서, 사회적 발달에 영향을 미친다고 보고되고 있다(Bretherton, 1999; Jo, 2008; Y. Lim, 2014). 즉, 중학교 1학년 인 초기 청소년기에 부모로부터 느끼는 애착은 부모의 여부에 의한 실제적인 영향력은 줄어들지만, 언제나 자신이 필요로 할 때 자기편이 되어 줄 수 있는 신념으로 변환되기 때문에, 초 기 청소년기의 부모애착은 여전히 중요하다(Lee \& Min, 2013).

부모애착은 청소년이 어떤 문화권에서 성장하고 생활하는 지에 관계없이 적응을 가능하게 하는 보편적인 기제로서, 부 모에 대한 안정된 애착관계의 형성은 학업성취, 학습동기, 사 회적 관계, 정서적 안정, 자아존중감, 학교규칙 준수 등을 향 상시켜서, 청소년들로 하여금 학교생활에 성공적으로 적응하 도록 하며, 성인기에 경험하게 되는 인지적, 사회적 경험들에 능동적이며 긍정적으로 적응하도록 하여 건강한 발달을 돕기 때문에 매우 중요하다(Angus, 2013; Bowlby, 1982). 청소년들 은 학업에 대한 중압감 등 스트레스 요인이 많은 발달적 과도 기에 있다. 이 시기에 가정에서의 안정적인 부모애착은 청소 년의 대인적 관계뿐만 아니라 학교생활적응에 결정적으로 기 여하게 된다(Kim, 2015). 즉, 부모와의 애착관계는 다른 어떤 관계보다 친밀하고 중요한 영향을 미치게 되며, 청소년의 학 교생활적응에 있어서 중요한 요인이 된다. 청소년의 부모애 착이 학교생활적응에 미치는 선행연구들은 대체적으로 일관 된 결과를 제시하고 있다. Cho와 Seo (2010), Choi (2005), Hur 와 $\mathrm{Kim}$ (2005), Kim, Lee, 그리고 Bae (2012), Laghi, D’Alessio, Pallini, 그리고 Baiocco (2009), Moon (2002), E. Park (2010), Y. Park (2010), Park, Hong, 그리고 Chung (2014) 등은 부모와의 
안정적인 애착을 형성할수록 학교생활에 잘 적응한다고 하였 으며, Howes와 Hamilton (1993)은 부모와의 불안정한 애착관 계를 갖는 학생은 학교부적응을 유발하는 위험요인이라고 하 였다. 또한 Williams와 Kelly (2005)는 부모와의 애착경험은 친 구를 포함한 가족 외의 사람들과의 관계에도 영향을 미치며, 이후의 발달과 다양한 적응에도 영향을 미친다고 하였다.

또한 부모애착은 인터넷사용유형과 영향관계가 있는 것으 로 보고되고 있다. Nam (2001)은 부모애착 수준이 높은 청소 년이 학습추구형 인터넷사용에는 긍정적인 영향을 보인 반 면, 부모애착은 청소년들의 음란물과 같은 오락추구형과 여 가활동, 채팅 등 관계추구형에는 영향이 없다는 것을 밝혔다. Hwang (2005)은 중학생을 대상으로 인터넷사용유형을 음란 추구형, 언어폭력형, 학습추구형, 관계지향형으로 구분하여 연구를 수행한 결과, 부모애착은 음란추구형과 오락추구형 등 과 같은 인터넷사용유형에는 부정적인 영향관계를 보인 반면, 학습추구형과 관계지향형 등에는 긍정적인 영향이 있는 것 으로 나타났다. 국외의 연구에서 Lee와 Chae (2007)와 Rosen, Cheever, 그리고 Carrier (2008)는 부모와의 애착정도가 높고 부 모가 자녀와 함께 학습 등의 목적으로 유익한 사이트를 탐색 하는 행위는 청소년의 학습 등의 건전한 인터넷 사용에 영향 을 미친다고 하였다. 또한 Aunola, Stattin, 그리고 Nurmi (2000) 는 부모애착이 높은 청소년들은 학습을 추구하는 등 건전한 인터넷 이용을 하는 한편, 낮은 부모애착을 가진 청소년들은 부정적인 인터넷 이용을 한다고 하였다. 사회통제이론을 제시 한 Hirschi (1969)는 부모의 양육태도 중 부모애착이 가장 중요 한 요소라고 하면서, 부모와의 애착수준이 높은 청소년들은 사회와 강한 유대관계를 보임에 따라 인터넷 일탈을 하지 않 는 반면, 부모애착이 낮은 청소년들은 사회와의 유대관계가 낮아 부정적인 인터넷활용을 한다고 하였다.

청소년의 인터넷사용은 꾸준히 증가하고 있다. Korea Internet \& Security Agency (2014)에 의하면, 우리나라 청소년 의 $99.7 \%$ 가 인터넷을 사용하고 있다고 하였다. 이러한 비율 은 세계 어느 나라보다 높은 수치로, 중국의 $89.0 \%$, 일본의 $94.7 \%$ 보다도 높은 것으로 나타났다. 이와 같이 청소년의 인터 넷 이용이 보편화된 상황에서 그들의 인터넷 이용이 학교생활 에 어떠한 영향이 있을지에 대한 관심 또는 증가하고 있다. 그 러나 청소년을 대상으로 인터넷이 학교생활적응에 미치는 영 향에 대한 연구 대부분은 인터넷 중독에 대해 관심을 두고 있 을 뿐만 아니라 인터넷 이용이 유발하는 부정적인 영향에 주 로 관심을 두고 있었다(Byun \& Kim, 2007; Ju \& Cho, 2013; Kim \& Baik, 2011; Ministry of Science, ICT and Future Planning
[MSIP] \& National Information Society Agency [NIA], 2015). 그 결과 일상적으로 인터넷을 이용하고 있는 우리나라의 청소년 들에게 인터넷 이용이 그들의 삶과 학교생활에서 어떠한 영향 이 있는지에 대한 관심이 매우 미진한 현실이다.

반면, 청소년의 인터넷 이용의 긍정적인 영향에 대한 연구 도 일부 보고되고 있다. 2014년 인터넷이용실태조사결과, 우 리나라 청소년들의 인터넷 이용실태(중복응답)는 자료 및 정 보획득이 $93.7 \%$, 교육 및 학습이 $56.9 \%$ 로 나타났다(MSIP \& NIA, 2015). 이와 같이 청소년의 인터넷 이용에 대한 선행연구 들의 대부분은 부정적인 영향으로 보고되고 있지만, 그들의 인터넷 이용이 그들의 학교생활에 있어 긍정적인 영향이 있다 는 일부 연구결과를 통해, 인터넷 이용이 청소년들의 학교생 활적응에 유의한 영향을 미친다는 것은 분명해 보인다.

또한 청소년의 인터넷사용은 학교생활적응에 영향을 미치 는 요인으로 보고되고 있다. Cho (2009), Han과 Kim (2006), Lee (2010) 등은 청소년의 인터넷의 과도한 사용은 청소년의 학업성취도 저하와 중도탈락 등 학교생활에서의 부적응 문제 를 일으키는 요인이라고 하였다. 한편 최근 일부연구에서 청 소년의 인터넷사용이 폭력게임이나 음란물 등에 노출될 시에 는 청소년에게 유해할 수 있지만, 정보를 검색하거나 관계를 도모하기 위한 목적으로 인터넷을 사용할 때에는 청소년에게 오히려 이로울 수 있다는 연구가 보고되고 있다. Cho와 Kim (2009)은 청소년의 인터넷이용시간은 학교생활적응에 영향이 없는 반면, 인터넷사용내용에 따라 학교생활적응은 영향을 달 리한다고 하였다. 즉, 오락과 같은 인터넷 이용은 학교성적을 떨어뜨림에 따라 학교생활적응을 어렵게 하는 반면, 정보를 검색하기 위한 용도로 인터넷을 이용하는 경우에는 학교성적 이 향상되고 학교생활적응을 잘한다는 것이다.

인터넷사용유형을 관계지향형, 학습추구형, 오락추구형 등 으로 구분하여 청소년의 학교생활적응에 미치는 영향을 연구 한 Jang과 $\operatorname{Kim}$ (2008)은 관계추구형은 친구와 교사와의 관계 를 향상하지만 학교생활적응에는 영향을 미치지 않으며, 오 락추구형은 친구와의 관계에는 영향이 없으나 교사와의 관계 를 악화하여 학교생활적응에는 부정적인 영향이 있는 반면, 정보추구형은 친구와의 관계에는 영향이 없으나 교사와의 관 계를 향상하여 학교생활적응에 긍정적인 영향을 보인다고 하 였다. S. $\operatorname{Lim}$ (2014)은 청소년들의 인터넷 사용유형 중 관계추 구형은 학교생활적응에 영향이 없었으며, 오락추구형은 학교 생활적응에 부정적인 영향을 보인 반면, 정보추구형은 오히 려 학교생활적응에 이로운 영향을 보임을 밝혔다. 또한 Kim, Cho, Cheong, 그리고 $\operatorname{Lim}$ (2011)은 인터넷사용유형 중 관계추 
구형은 학교생활적응에 영향이 없다는 선행연구를 토대로 오 락추구형과 학습추구형으로 구분하여 청소년의 학교생활적 응에 미치는 영향관계를 살펴본 결과, 오락추구형은 학교생활 적응에 부정적인 영향을 미쳤으며, 학습추구형은 학교생활적 응에 긍정적인 영향이 있음을 밝혔다. 반면, 중학교 1, 2학년 을 대상으로 연구한 Kim과 Chung (2010)은 오락추구형은 학 교생활적응에 영향이 없게 나타났으며, 학습추구형 인터넷사 용이 증가할수록 학교생활적응을 잘하는 것을 발견하였다. 이 를 통해 인터넷사용이 무조건적으로 학교생활적응에 부정적 인 영향만 있는 것이 아니라 긍정적인 영향이 있음을 확인하 였으며, 따라서 청소년들의 인터넷사용을 단순한 빈도나 중독 에 따른 학교생활적응의 영향력 분석에 추가하여 인터넷사용 유형별 인터넷이용에 따른 학교생활적응에 대한 연구가 필요 함을 알 수 있었다.

이상에서 살펴본 바와 같이 부모와의 불안정적인 애착관계 를 형성한 청소년일수록 학교생활에 잘 적응을 하지 못한다. 하지만 청소년의 부모애착과 학교생활적응 간의 관계에서 그 들의 학교생활적응을 향상시키려는 연구는 그리 많지 않은 실 정이다. 이와 같은 상황에서 그들을 대상으로 부모애착, 인터 넷사용유형, 그리고 학교생활적응에 대한 연구들이 일부 진행 되고 있는 것은 매우 고무적이다. 특히 부모애착이 청소년의 인터넷사용유형에 영향을 미치고, 인터넷사용유형이 학교생 활적응에 영향이 있다는 선행연구는 인터넷사용유형이 부모 애착과 학교생활적응 간을 매개한다는 것을 유추할 수 있게 한 다. 하지만 이들 연구 대부분이 부모애착과 학교생활적응 간 의 연구 또는 인터넷의 단순한 이용시간 또는 인터넷중독 등의 매체중독 관련요인과 학교생활적응의 연관연구 등과 같은 단 편적인 연구가 대부분이다(Jang \& Kim, 2008; Lee \& Lee, 2006; S. Lim, 2014). 즉, 부모애착과 학교생활적응 간의 관계에서 학 교생활적응을 높이고자 하는 매개효과에 대한 연구는 부모와 의 불안정적인 애착관계와 학교비행 간의 관계에서 인터넷 중 독이 이들 간을 매개한다는 연구(Jeong \& Park, 2012), 부모애착 과 학교생활적응 간의 관계에서 자아존중감이 매개한다는 연 구(Kim, 2011), 부모애착과 학교생활적응 간의 관계에서 적응 적 방어기재가 매개한다는 연구(Kim et al., 2012) 등 제한적으 로 보고되고 있다. 특히 청소년의 인터넷사용유형별 인터넷이 용을 매개변수로 하여, 이들 요인들이 청소년의 부모애착과 학 교생활적응 간의 관계에서 어느 요인이 학교생활적응을 높여 주는 요인인지를 검증하는 연구는 연구가 많지 않은 실정이다.

따라서 기존의 제한적인 영향관계를 넘어서 초기 청소년의 부모애착과 학교생활적응 간의 영향관계에서 학교생활적응
을 높이기 위해 새로운 요인변수로서의 매개변수를 찾아내는 것은 매우 중요하다. 이와 같은 시도는 초기 청소년의 학교생 활적응에 미치는 영향 뿐 아니라 청소년 교육 및 청소년복지 정책의 차원에서도 많은 공헌이 있을 것으로 기대된다. 또한 본 연구는 인터넷 이용이 대다수의 선행연구에서 밝혀진 바와 같이 부정적인 영향관점뿐만 아니라 이로운 점이 있다는 일부 선행연구를 토대로 그들의 학교생활에서의 사고, 인식, 행동 에 어떠한 영향을 줄 것인가에 대한 일부 해답을 제공할 것이 라고 판단하였다.

이에 본 연구는 선행연구를 토대로, 중학교 1 학년인 초기 청소년들이 인식하는 부모애착이 직접적으로 학교생활적응 에 영향을 미치고, 인터넷사용유형별 인터넷이용이 이들 간의 관계에서 매개효과가 있는지를 검증하고자 하였다. 이를 통해 본 연구는 그들의 학교생활적응을 높이는데 기여하고자 하며, 이를 통해 그들 개개인의 낮은 학교생활적응으로 인한 다양한 문제뿐만 아니라 사회적인 문제도 해소될 수 있도록 실천적, 정책적인 관점에서의 기초자료를 제공하는 것을 목적으로 한 다. 이러한 목적을 위해 설정한 연구모형은 Figure 1과 같으며, 연구문제는 다음과 같다.

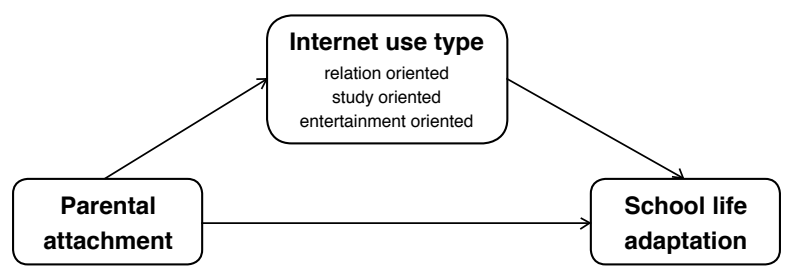

Figure 1. Research model

\section{연구문제 1}

초기 청소년의 부모애착과 학교생활적응은 어떠한 관계를 가 지는가?

\section{연구문제 2}

초기 청소년의 부모애착은 인터넷사용유형(관계지향형/학습 추구형(오락추구형)을 매개로 하여 학교생활적응에 영향을 미치는가?

\section{연구방법}

\section{1. 연구대상}

본 연구에서는 한국청소년정책연구원(National Youth Policy 
Institute [NYPI])에서 실시한 한국아동청소년패널조사의 초 등학교 4학년 패널 4차 년도 자료(현 중학교 1학년)를 활용하 였다. 한국아동청소년패널조사는 초등학생과 중학생을 조사 대상으로 학령기 전반에 관한 포괄적인 기초자료를 효율적으 로 확보하고자 3 개(초1, 초4, 중1)의 연령 코호트를 설정하여 2010년부터 2016년까지 7년간 추적 조사하는 단기종단 패널 조사이다(NYPI, 2014). 본 연구에서는 2010년에 층화다단계 집락표집법에 의해 초등학교 4학년 패널에서 선정된 이후로 중학교 1학년이 된 2013년에 구축하여 2014년 배포한 4차 년 도 데이터를 사용하였다. 본 연구에서는 중학교 1학년의 경우 2차 성징에 의한 생물학적 변화 뿐 아니라 사회적 관계변화도 경험하는 시기로서, 부모로부터 느끼는 애착은 그 이전 시기 보다는 그 영향력은 줄어들지만, 부모는 안전기지로서 부모애 착은 여전히 중요하다고 한 $\operatorname{Kim}$ (2015)과 Lee와 Min (2013)을 토대로, 초기청소년에 해당하는 중학교 1학년 학생들의 자료 만을 사용하였다.

한국아동청소년패널은 총 2,378 명의 중학교 1 학년 학생을 제공하며, 본 연구에서는 설정한 변수들을 대상으로 빈도분석 을 수행하여 결측치를 제거한 결과, 최종 1,537 명의 중학교 1 학년을 대상으로 연구를 수행하였다.

\section{2. 연구도구}

\section{1) 독립변수 : 부모애착}

부모애착은 Huh (2000), Kim (2003) 등을 참조하여 아동청소 년패널조사에서 구성한 부모의 양육방식을 묻는 다양한 문항 (지도감독, 부모애착, 과잉기대, 과잉간섭, 합리적 설명, 방임, 학대) 중 부모애착에 해당하는 4 개의 문항을 부모애착 척도로 사용하였다. 이 척도는 "나의 의견을 존중해 주신다", "내게 좋 아한다는 표현을 하신다", "내가 힘들어 할 때 용기를 주신다", "나에게 칭찬을 잘 해 주신다" 등으로 되어 있다. 각 문항은 4 점 Likert 척도 $(1$ 점 $=$ 매우 그렁다, 4 점 $=$ 전혀 그렇지 않다 $)$ 로 구성되어 있는 것을 분석의 편의를 위해 역으로 변환한 후 평 균을 구한 후 분석에 활용하였다. 따라서 점수가 높을수록 부 모애착 수준이 높음을 의미한다. 본 연구에서 척도의 신뢰도 계수인 Cronbach's $\alpha$ 는 .819이었다.

\section{2) 종속변수 : 학교생활적응}

학교생활적응 척도는 $\operatorname{Min}$ (1991)이 개발한 도구를 바탕으로
한국아동청소년패널조사에서 사용한 20 개 문항을 사용하였 다. 이 척도는 학습활동 5문항(예: 학교 수업 시간이 재미있 다), 학교규칙 5 문항(예: 반에서 맡은 활동을 열심히 한다), 교 우관계 5 문항(예: 우리 반 아이들과 잘 어울린다), 교사관계 5 문항(예: 선생님을 만나면 반갑게 인사한다)이다. 각 문항은 4 점 Likert 척도 $(1$ 점 $=$ 매우 그렇다, 4 점 $=$ 전혀 그렇지 않다 $)$ 로 “공부 시간에 딴 짓을 한다”, “친구가 하는 일을 방해 한다”를 제외한 문항은 역으로 합산하여 평균을 구하여 분석에 사용하 였다. 따라서 본 연구에서는 해당 점수가 높을수록 학교생활 적응 수준이 높음을 의미한다. 본 연구에서의 Cronbach's $\alpha$ 는 .892로 나타났다.

\section{3) 매개변수 : 인터넷사용유형}

본 연구에서의 매개변수로는 한국아동청소년패널조사에서 정의한 인터넷이용을 설정하였다. 인터넷이용은 아동청소년 패널조사에서 정의한 학습관련, 게임 및 오락관련, 19 세 이상 사이트 이용 등과 같은 10 개의 문항을 사용하였다. Jang과 Kim (2008), Kim (2013), 그리고 Kim과 Chung (2010)은 이들 문항 들을 “채팅하기/ 메신저 사용", “전자우편 이용”, “동호회/ 까 페/ 커뮤니티활동”, “개인 홈페이지 활동”, “온라인 거래”, “게 시판 활동”의 6문항을 관계지향형으로, "컴퓨터 게임”, “성인 용사이트 열람”의 2문항을 오락추구형으로, “공부 및 학습관 련 정보 검색, 열람”, “기타 정보 검색, 열람”의 2문항을 학습추 구형으로 구분하였다.

본 연구에서는 이들 선행연구를 토대로 요인추출방법을 주 성분 분석으로, 요인회전은 일반적으로 많이 사용하는 직교회 전방식인 베리멕스를 지정하여, 인터넷이용 관련 10 개의 문 항에 대한 탐색적 요인분석을 수행하였다. 그 결과, 모든 문항 들의 요인적재량이 .45를 넘었으며, Jang과 Kim (2008), Kim (2013), 그리고 Kim과 Chung (2010)와 동일하게 관계지향형 6 문항, 오락추구형 2 문항, 정보지향형 2문항 등 3 개의 요인이 추출되었다. 각 문항은 해석편의를 위하여 $1=$ 자주 하지 않는 다에서 $4=$ 자주 한다의 4 점 척도로 역채점하여, 평균값을 구 하여 사용하였다. 따라서 점수가 높을수록 관계지향형, 학습 추구형, 오락추구형 등의 인터넷이용이 많은 것을 의미한다.

\section{4) 통제변수}

본 연구에서는 학교생활적응 관련 선행연구를 토대로 통제변 수를 다음과 같이 설정하였다. 먼저 성별은 $0=$ 여학생, $1=$ 남 
학생으로 더미처리 하였으며, 부 연령과 모 연령은 회귀분석 에서는 연속형 변수를 그대로 사용하였으며, 빈도분석을 위해 서 $1=40$ 세 미만, $2=40$ 대, $3=50$ 대, $4=60$ 세 이상으로 변환하 였다. 부 학력과 모 학력은 $1=$ 중졸 이하, $2=$ 고졸, $3=$ 전문대 졸, $4=$ 대졸, 5 = 대학원졸로 구성되었다. 부의 근로 여부와 모 의 근로 여부는 $0=$ 일을 하고 있지 않다, $1=$ 일을 하고 있다로 더미처리 하였다. 가구 연소득은 회귀분석에서는 연속형 변수 를 그대로 사용하였으며, 빈도분석을 위해서 $1=3$ 천만원 미 만, $2=3$ 천만원 -5 천만원 미만, $3=5$ 천만원-7천만원 미만, $4=$ 7 천만원 이상으로 재구성하였다. 본인건강상태는 역으로 되 어 있는 것을 분석을 용이하게 하기 위해 $1=$ 매우 건강하지 못 하다, 4 = 매우 건강하다로 역채점하였다. 성적만족도는 역으 로 되어 있는 것을 전혀 만족하지 않는다, $4=$ 매우 만족한다로 역채점하였다. 월용돈은 회귀분석에서는 연속형 변수를 그대 로 사용하였으며, 빈도분석에서는 $1=2$ 만원 미만, $2=2$ 만원 -5 만원 미만, $3=5$ 만원 이상으로 변환하여 분석하였다.

\section{3. 자료분석}

자료분석은 SPSS 20.0 (IBM Co., Armonk, NY)을 활용하였다. 먼저, 대상자의 인구사회학적 특성을 분석하기 위해 빈도 및 백분율을 산출하였으며, 부모애착과 학교생활적응 간의 영향 력 및 인터넷사용유형별 인터넷이용의 다중매개효과를 밝히 기 위해 Preacher와 Hayes (2008)가 개발한 SPSS Indirect macro 를 이용하여 부트스트랩 절차(Bootstrapping)로 분석하였다. 최근에는 매개모형에서 간접효과를 확인하기 위해 Sobel 검증 보다는 부트스트랩 절차의 사용을 권장하고 있다. 왜냐하면 Sobel 검증은 정규분포를 가정할 때에 사용이 가능하며 단일 매개요인만을 검증하지만, 부트스트랩 절차는 여러 개의 매개 요인을 동시에 검증할 수 있는 장점을 갖고 있다. 부트스트랩 절차는 다중매개효과를 분석할 경우, 전체 매개변인에 대한 총 간접효과를 검증할 수 있고, 공변인(covariate)과 다른 매개 변인을 통제하면서 각 매개변인에 대한 개별 간접효과의 검증 이 가능하고, 제시된 모형의 정확성과 간명성을 높일 수 있고, 사용이 편리하다는 장점이 있다(Hur, 2013). 이 분석법에서 매 개효과의 확인은 매개효과의 유의성 결과에서 나타난 신뢰구 간 내의 간접효과 값에 0 이 포함되지 않으면 매개효과가 있는 것으로 판단한다. 부트스트랩의 사례수는 연구자에 따라 제안 하는 횟수는 다르나, 본 연구에서는 Shrout와 Bolger (2002)가 추천한 5,000 번을 설정하였다.

\section{결과분석}

\section{1. 연구대상자의 일반적 특성}

본 연구대상자의 일반적 특성은 Table 1 과 같다. 분석결과, 성 별은 남학생이 839명(54.6\%)로서 여학생 698명(45.4\%)보 다 조금 높은 분포를 보였다. 부 연령은 40 대가 $81.1 \%$ 로 대부 분을 차지했으며, 모 연령도 40 대가 $74.4 \%$ 를 차지하였다. 부 학력은 대졸이 $43.4 \%$ 로서 가장 높은 분포를 보였으며, 고졸 이 $37.4 \%$, 전문대졸이 $10.9 \%$, 대학원졸이 $6.1 \%$, 중졸 이하가 $2.1 \%$ 순으로 분포되었다. 모 학력은 고졸이 $45.0 \%$ 이 가장 높 은 분포를 보였으며, 대졸이 $35.5 \%$, 전문대졸이 $15.0 \%$, 대학 원졸이 $2.8 \%$, 중졸 이하가 $1.8 \%$ 순으로 분포되었다. 아버지 는 $98.4 \%$ 가 일을 하고 있었으며, 어머니는 $62.5 \%$ 가 일을 하 는 것으로 나타났다. 가구 연소득은 3 천만 원에서 5 천만 원 미 만이 $40.8 \%$ 로 가장 많았으며, 5 천만 원에서 7천만 원 미만이 $31.7 \%, 7$ 천만 원 이상이 $15.8 \%, 3$ 천만 원 미만이 $11.7 \%$ 순으 로 분포되었다. 청소년들은 $95.1 \%$ 가 건강한 상태였으며, 성적 에 대해 만족하는 학생들은 $56.5 \%$ 로 나타났다. 월용돈은 2 만 에서 5 만 원 미만이 $66.6 \%$ 로서 가장 높은 분포를 보였으며, 5 만 원 이상이 $22.7 \%, 2$ 만 원 미만이 $11.7 \%$ 순으로 분포되었다.

\section{2. 주요변수의 특성}

주요변수들의 특성을 살펴본 결과는 Table 2 와 같이, 모든 척 도는 4점 척도로 구성되어 있다. 독립변수인 부모애착은 평균 이 3.19로서 부모애착 수준이 비교적 높은 것을 알 수 있었다. 매개변수인 인터넷사용유형 전체는 2.64 로서 보통정도의 수 준으로 나타났으며, 하위변수인 관계지향형은 1.98 로서 다소 낮은 수준, 학습추구형은 2.91로서 보통보다 조금 높은 수준, 오락추구형은 2.50 으로서 보통 수준의 인터넷이용을 보였다. 종속변수인 학교생활적응은 3.01으로서 다소 높은 수준임을 알 수 있었다. 또한 왜도와 첨도 등의 살펴본 결과, 정규분포의 기준값인 왜도(Skewness) \pm 2 이하, 첨도(Kurtosis) \pm 4 이하의 기준 을 모두 충족함에 따라 이들 변수들은 정규분포를 이루고 있 다고 할 수 있었다(Bae, 2007).

3. 부모애착과 학교생활적응 간 인터넷사용유형별 인터넷이용의 매개효과

본 연구는 SPSS Indirect macro를 활용하여 Preacher와 Hayes 
Table 1

Demographic Characteristics

$(N=1,537)$

\begin{tabular}{|c|c|c|c|}
\hline Variable & Category & Frequency & $\%$ \\
\hline \multirow[t]{2}{*}{ Gender } & Girl & 698 & 45.4 \\
\hline & Boy & 839 & 54.6 \\
\hline \multirow[t]{4}{*}{ Father's age } & Under 40 & 93 & 6.1 \\
\hline & $40-49$ & 1,246 & 81.1 \\
\hline & $50-59$ & 193 & 12.6 \\
\hline & 60 and above & 5 & 0.3 \\
\hline \multirow[t]{4}{*}{ Mother's age } & Under 40 & 338 & 22.0 \\
\hline & $40-49$ & 1,143 & 74.4 \\
\hline & $50-59$ & 56 & 3.6 \\
\hline & 60 and above & - & - \\
\hline \multirow[t]{5}{*}{ Father's education level } & Middle school and below & 33 & 2.1 \\
\hline & High school & 575 & 37.4 \\
\hline & College & 168 & 10.9 \\
\hline & University & 667 & 43.4 \\
\hline & Graduate school and above & 94 & 6.1 \\
\hline \multirow[t]{5}{*}{ Mother's education level } & Middle school and below & 27 & 1.8 \\
\hline & High school & 692 & 45.0 \\
\hline & College & 230 & 15.0 \\
\hline & University & 545 & 35.5 \\
\hline & Graduate school and above & 43 & 2.8 \\
\hline \multirow[t]{2}{*}{ Father's employment } & No & 24 & 1.6 \\
\hline & Yes & 1,513 & 98.4 \\
\hline \multirow[t]{2}{*}{ Mother's employment } & No & 577 & 37.5 \\
\hline & Yes & 960 & 62.5 \\
\hline \multirow[t]{4}{*}{ Family income a year } & Under 30 million won & 180 & 11.7 \\
\hline & 30 Million-50 million won & 627 & 40.8 \\
\hline & 50 Million-70 million & 487 & 31.7 \\
\hline & 70 Million won and above & 243 & 15.8 \\
\hline \multirow[t]{4}{*}{ Adolescent health status } & Severely low & 5 & 0.3 \\
\hline & Low & 71 & 4.6 \\
\hline & Good & 960 & 62.5 \\
\hline & Very good & 501 & 32.6 \\
\hline \multirow[t]{4}{*}{ Grade satisfaction } & Severely low & 108 & 7.0 \\
\hline & Low & 560 & 36.4 \\
\hline & Good & 718 & 46.7 \\
\hline & Very good & 151 & 9.8 \\
\hline \multirow[t]{3}{*}{ Monthly allowance category } & Under 20,000 won & 180 & 11.7 \\
\hline & $20,000-50,000$ won & 1,023 & 66.6 \\
\hline & 50,000 won and above & 334 & 21.7 \\
\hline
\end{tabular}


Table 2

Technical Statistics Major Variables

\begin{tabular}{lccccccc}
\hline \multicolumn{1}{c}{ Variable } & $N$ & Min & Max & M & SD & Skewness & Kurtosis \\
\hline Parental attachment & 1,537 & 1 & 4 & 3.19 & .56 & -.41 & -.36 \\
Internet use type & 1,537 & 1 & 4 & 2.64 & .54 & -.31 &. .04 \\
Relation oriented & 1,537 & 1 & 4 & 1.98 & .71 & .35 & -.57 \\
Study oriented & 1,537 & 1 & 4 & 2.91 & .73 & -.70 & .32 \\
Entertainment oriented & 1,537 & 1 & 4 & 2.50 & .60 & -.30 & -.26 \\
School life adaptation & 1,537 & 1 & 4 & 3.01 & .42 & .55 \\
\hline
\end{tabular}

(2008)가 제안한 절차에 따라 부모애착과 학교생활적응 간 인 터넷사용유형별 인터넷이용의 매개효과를 검증하였다.

\section{1) 학교생활적응에 대한 일반적 변인들의 영향력}

학교생활적응에 대한 일반적 변인들의 영향력을 살펴본 결과 는 Table 3 과 같이 나타났다. 분석결과, 통제변수들은 본인의 건강상태가 좋을수록, 성적만족도가 높을수록, 남학생일수록 학교생활적응을 잘하는 것을 알 수 있었다.

\section{2) 부모애착과 학교생활적응 간 인터넷사용유형별 인터넷이용 의 매개효과 검증}

매개효과를 검증하기 위해 본 연구에서 설정한 모든 통제변수 를, 독립변수로서 부모애착을, 매개변수로서 인터넷사용유형 (관계지향형/학습추구형/오락추구형)을, 종속변수로서 학교
생활적응을 투입한 상태에서 SPSS Indirect macro를 수행한 결 과, Table 4 및 Figure 2와 같이 나타났다.

분석절차의 첫 번째 단계는 매개변인이 없는 모형분석으 로, 부모와의 애착이 잘 형성될수록 학교생활적응이 잘되 는 관계에 있는 것을 확인하였다(가설 1 은 지지됨, Table 4와 Figure 2의 a: $B=.336, p<001)$.

두 번째 단계는 매개효과 검증으로서 Figure 2의 b와 c와 같 이 인터넷사용유형별 인터넷이용의 매개변수가 동시에 투입 된 이후에 부모애착은 학교생활적응에 영향을 미치는 것으로 확인되었다(Figure 2의 b: $B=.309, p<001$ ). 또한 매개변인인 인터넷이용의 하위변수 중에서 학습추구형 인터넷사용은 부 모애착으로부터 정적(+)인 영향을 받았으며, 학교생활적응에 는 정적인 영향을 미치는 것으로 나타났다. 또한 오락추구형 인터넷사용은 부모애착으로부터 부적(-)인 영향을 받았으며, 학교생활적응에는 부적인 영향을 미치는 것으로 나타났다. 반 면, 관계지향형은 부모애착과 학교생활적응 모두에서 직접적

Table 3

Effect on School Life Adaptation

\begin{tabular}{lccc}
\hline \multicolumn{1}{c}{ Variable } & $B$ & $S E$ & $t$ \\
\hline Gender & .059 & .021 & $2.818^{* *}$ \\
Father's age &. .003 & .003 &. .967 \\
Mother's age & .001 & .004 & .789 \\
Father's education level & .006 & 012 & .504 \\
Mother's education level & .010 & .013 & .722 \\
Father's employment & .031 & .073 & .423 \\
Mother's employment & -.013 & .019 & -.721 \\
Family income a year & .000 & .000 & .796 \\
Adolescent health status & .084 & .016 & $5.111^{* * *}$ \\
Grade satisfaction & .057 & .012 & .003 \\
Monthly allowance & -.003 & & -.590 \\
\hline
\end{tabular}

${ }^{* *} p<.01 .{ }^{* * *} p<.001$. 


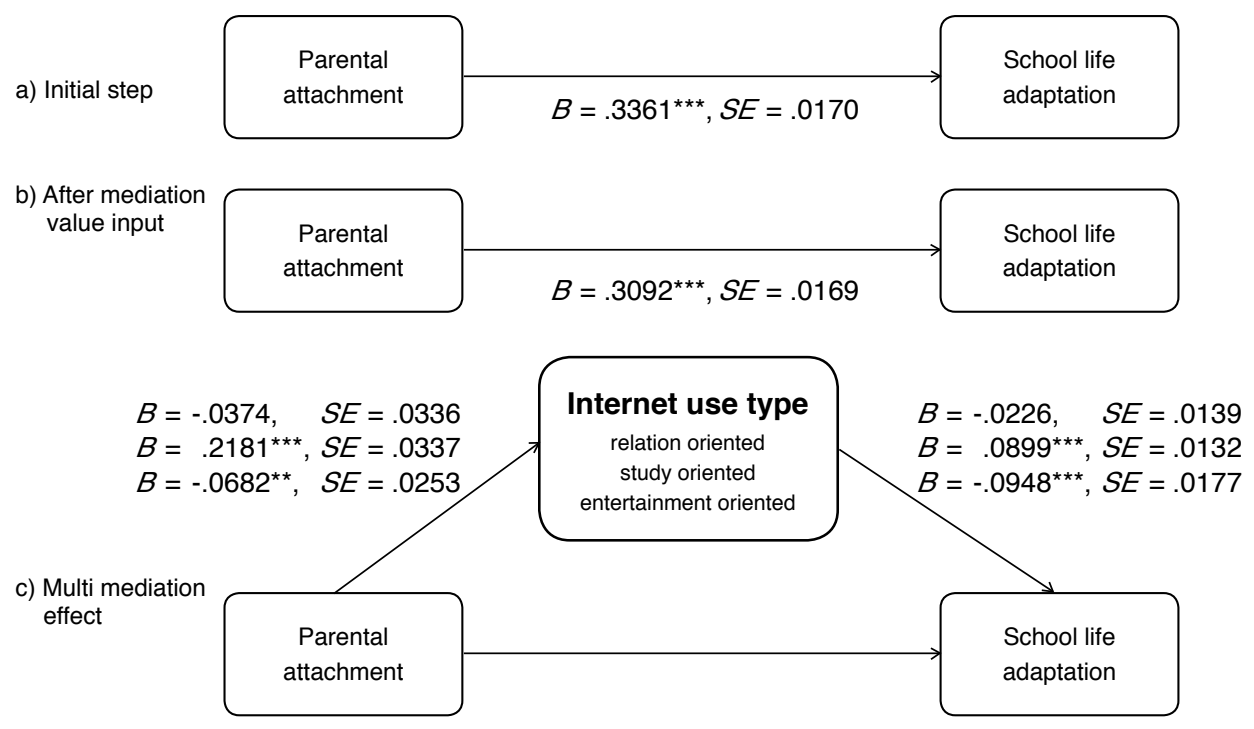

Figure 2. Validation of multiple mediating effect.

${ }^{* *} p<.01 .{ }^{* * *} p<.001$.

인 영향관계가 나타나지 않았다(Figure 2의 c).

세 번째 단계는 매개효과에 대한 유의성 검증으로, Shrout 와 Bolger (2002)가 제안한 부트스트래핑 절차를 적용하여 분 석을 통해 유의성을 확인하였다. 인터넷이용의 하위변수인 관 계지향형, 학습추구형, 오락추구형에 대한 매개효과의 유의성 을 검증한 결과, Table 5 와 같이 인터넷이용의 하위변수 각각 의 매개효과에 있어, 부모애착이 학습추구형 인터넷사용을 거 쳐 학교생활적응으로 가는 경로 $(B=.020)$ 는 $95 \%$ 신뢰구간에 서 BC $[.012, .030]$ 가 0 을 포함하지 않음에 따라, 학습추구형 인
터넷사용은 부모애착과 학교생활적응을 매개하는 것을 확인 하였다(가설 2-2는 지지함). 또한 부모애착이 오락추구형 인터 넷사용을 거쳐 학교생활적응으로 가는 경로 $(B=.007)$ 는 $95 \%$ 신뢰구간에서 $\mathrm{BC}[.002, .013]$ 가 0 을 포함하지 않음에 따라, 오 락추구형 인터넷사용은 부모애착과 학교생활적응을 매개하 는 것을 확인하였다(가설 2-3은 지지함). 반면, 부모애착이 관 계지향형 인터넷사용을 거쳐 학교생활적응으로 가는 경로 $(B=.001)$ 는 $95 \%$ 신뢰구간에서 $\mathrm{BC}[-.000, .005]$ 가 0 을 포함 함에 따라, 관계지향형 인터넷사용은 부모애착과 학교생활적

Table 4

Path Coefficient of Major Variables

\begin{tabular}{|c|c|c|c|}
\hline Path & Coefficient & $S E$ & $t$ \\
\hline Parental attachment $\rightarrow$ Relation oriented & -.037 & .034 & -1.114 \\
\hline Parental attachment $\rightarrow$ Entertainment oriented & -.068 & .025 & $-2.699^{* *}$ \\
\hline Relation oriented $\rightarrow$ School life adaptation & -.023 & .014 & -1.621 \\
\hline Study oriented $\rightarrow$ School life adaptation & .090 & .013 & $6.808^{* * *}$ \\
\hline Entertainment oriented $\rightarrow$ School life adaptation & -.095 & .018 & $-5.342^{* * *}$ \\
\hline
\end{tabular}

${ }^{* *} p<.01 .{ }^{* * *} p<.001$. 
Table 5

Significance Validation of Mediating Variable

\begin{tabular}{|c|c|c|c|c|}
\hline \multirow[b]{2}{*}{ Mediating path } & \multicolumn{3}{|c|}{ Mediation effect } & \multirow{2}{*}{$\begin{array}{c}R^{2} \\
F\end{array}$} \\
\hline & $B$ & $S E$ & BC $95 \%$ CI & \\
\hline Parental attachment $\rightarrow$ Relation oriented $\rightarrow$ School life adaptation & .001 & .001 & {$[-.000, .005]$} & .3165 \\
\hline Parental attachment $\rightarrow$ Study oriented $\rightarrow$ School life adaptation & .020 & .005 & {$[.012, .030]$} & \\
\hline Parental attachment $\rightarrow$ Entertainment oriented $\rightarrow$ School aife adaptation & .007 & .007 & {$[.002, .013]$} & $46.9438^{* * *}$ \\
\hline
\end{tabular}

${ }^{* * *} p<.001$.

응을 매개하지 않는 것을 확인하였다(가설 2-1은 지지하지 않 음).

\section{논의 및 결론}

본 연구는 중학교 1학년인 초기 청소년들이 느끼는 부모애착 과 학교생활적응 간의 영향관계에서, 학교생활적응에 영향을 보일 것으로 예상되는 인터넷사용유형이 그들 간에 매개효과 가 있는지를 실증적으로 확인해봄으로써, 그들의 학교생활적 응을 높이기 위한 몇 가지 방안을 모색하고자 하였다. 이를 위 해 본 연구에서는 독립변수로서 부모애착, 매개변인으로 인 터넷사용유형별 인터넷이용, 그리고 종속변수로서 학교생활 적응을 설정하고, 이들 간 빈도분석, 기술통계, 그리고 SPSS Indirect macro를 수행하였으며, 연구결과를 토대로 논의를 하 면 다음과 같다.

첫째, 부모애착이 잘 형성될수록 학교생활적응을 잘 하는 것으로 나타난 본 연구결과는 대부분의 연구와 동일한 결과 였다(Cho \& Seo, 2010; Howes \& Hamilton, 1993; Hur \& Kim, 2005; Kim et al., 2012; E. Park, 2010; Y. Park, 2010). 둘째, 초 기 청소년의 부모애착수준이 높을수록 학교생활적응을 잘 하는 것으로 나타났다. 본 연구결과는 Cho와 Seo (2010), Hur 와 Kim (2005), Kim 등(2012), Laghi 등(2009), Moon (2002), E. Park (2010), Y. Park (2010), Park 등(2014) 등 대부분의 연구를 지지하였다.

셋째, 인터넷사용유형별 인터넷이용을 투입하여 매개효과 를 검증한 결과, 매개변인인 인터넷이용의 하위변수 중 학습 추구형 인터넷사용과 오락추구형 인터넷사용은 부모애착과 학교생활적응 간을 매개하는 것으로 나타난 반면, 관계지향형 은 부모애착과 학교생활적응 간을 매개하지 않는 것으로 나타 났다. 이를 통해 부모의 애착수준이 높은 경우에 학습지향형
과 같은 긍정적인 인터넷 사용이 증가하고 학교생활을 잘 한 다는 것과 오락지향형 인터넷 사용은 부모애착으로부터 부정 적인 영향과 함께 학교생활적응에도 부정적인 영향이 있다는 것, 그리고 관계지향형 인터넷사용은 부모애착으로부터 또는 학교생활적응 모두에 영향이 없다는 것 등을 알 수 있었다.

매개효과를 검증하는 과정에서 학습추구형 인터넷사용 이 증가할수록 학교생활적응을 잘한다는 결과와 오락추구형 인터넷사용이 증가할수록 학교생활적응을 잘하지 못한다는 결과는 대부분의 연구(Cho \& Kim, 2009; Jang \& Kim, 2008; Kim, Cho, Cheong, \& Lim, 2011; Kim, Lee, \& Yoon, 2011; S. $\mathrm{Lim}, 2014)$ 들이 지지한 반면, 오락추구형 인터넷사용이 학교 생활적응에 영향이 없다고 한 Kim과 Chung (2010)과는 상이 하였다. Kim과 Chung (2010)은 빈곤을 주요변수로 설정하고 어떠한 인터넷 사용유형이 학교생활적응을 매개하는지를 확 인한 결과, 정보추구형은 학교생활적응에 유의한 영향력을 보 인반면, 오락추구형은 유의하지 않게 나타났다. 이러한 일부 상이한 결과를 통해 우리사회의 초기 청소년들은 인터넷 사용 과 관련해서 개인 내적 특성이나 가족특성 등 다른 요인들을 고찰할 필요가 있는 것으로 보인다.

또한 관계지향형 인터넷사용이 학교생활적응에 영향이 없 는 것으로 나타난 본 연구결과는 Jang과 Kim (2008), Kim 등 (2011)의 연구와 동일하였다. 특히 본 연구에서 청소년의 학습 추구형 인터넷사용이 부모애착과 학교생활적응 간을 매개하 고, 학습추구형 인터넷사용이 증가할수록 학교생활적응을 잘 한다는 결과를 통해 인터넷이용이 선행연구와 같이 무조건적 으로 학교생활적응에 부정적인 영향만 있는 것이 아니라 긍정 적인 영향이 있음을 확인하였다.

본 연구는 부모애착이 초기 청소년의 학교생활적응에 영향 을 미치는데 있어서 인터넷사용유형이 이들 간을 매개하는 요 인이라는 것을 밝혔으며, 이를 통해 가정에서의 낮은 부모애 착으로 인해 낮아진 학교생활적응을 향상시킬 수 있는 기재 
로서 학습추구형 인터넷사용과 오락추구형 인터넷사용 요인 을 찾아냈다는데 의의가 있다. 이를 통해 인터넷이 생활화되 어 있는 우리사회의 초기 청소년들에게 인터넷이용이 무조건 부정적으로 작용할 것이라고 단정 짓는 것은 바람직하지 않으 며, 초기 청소년이 어떠한 이유로 인터넷을 사용하는지를 확 인하여, 오히려 인터넷 시대에 살아야 하는 청소년들이 부정 적인 인터넷사용은 자제시키고, 바람직한 방향으로 사용하도 록 학교에서는 그들을 교육하고 도와주는 것이 필요함을 시사 한다.

이상의 논의를 토대로 하여 제언과 함께 결론을 모색해 보 면 다음과 같다. 첫째, 중학교 1학년인 초기 청소년이 느끼는 부모애착이 그들의 학교생활적응에 긍정적인 영향이 있다는 것이 입증되었으며, 이를 통해 유아기와 아동기를 거쳐 초기 청소년기에도 부모애착은 그들의 심리사회적 적응에 영향을 미치는 중요한 변인임을 확인할 수 있었다. 즉, 부모에 대한 의 존에서 벗어나 자율성과 책임감을 획득하는 초기 청소년기이 지만, 여전히 부모와의 평등하고 애정적인 관계 및 지속적인 지원을 통하여 안정된 학교생활적응이 이루어진다는 것을 알 수 있었다. 따라서 이에 대한 제언으로는 초기 청소년의 학교 생활적응을 돕기 위해 학생뿐 아니라 부모-자녀관계를 연계 하여 살펴보아야 하며, 학교부적응으로 인한 상담은 학생과 더불어 부모상담도 병행되어야 할 것이다. 또한 초기 청소년 의 학교적응에 도움이 될 수 있는 부모-자녀간의 프로그램이 개발되어 부모와 자녀간의 관계가 증진될 수 있도록 도와야 한다. 이와 함께 가정에서 부모로부터 애착수준이 낮은 초기 청소년들을 대상으로 학교생활에 잘 적응할 수 있도록 부모나 교사들과 같은 주위 어른들의 많은 관심과 지원이 필요하다.

둘째, 오락추구형 인터넷사용 또한 부모애착과 학교생활적 응 간을 매개하는 것으로 나타났다. 또한 학습추구형 인터넷 사용이 부모애착과 학교생활적응 간을 매개한다는 본 연구결 과는 오락추구형과 학습추구형 인터넷사용이라는 매개요인 이 부모애착으로 인한 결과이면서 동시에 학교생활적응을 향 상시킬 수 있는 원인으로 작용될 수 있다는 것을 의미한다. 이 러한 연구결과는 먼저, 가정에서 부모의 안정적이지 못한 애 착으로 인해 초기 청소년의 학교생활부적응이 발생할 수 있 다는 점에서 부모애착을 잘 형성하는 것에 주목해야 한다. 이 와 함께 오락추구형 및 학습추구형 인터넷사용이 부모애착과 학교생활적응 간을 매개한다는 것은 초기 청소년의 학교생활 적응을 향상하기 위한 정책적이고 실천적인 노력이 오락추구 형 인터넷사용을 낮추고 학습추구형 인터넷사용을 높이는 측 면에서 이루어지는 것이 효과적임을 강조하게 된다. 이 중 학
습추구형 인터넷사용의 매개효과는 초기 청소년들이 가정에 서 부모와의 낮은 애착으로 인해 학교생활적응에 부정적인 영 향을 미치더라도 인터넷을 이용하여 정보를 잘 활용하는 초기 청소년들은 학교생활에서의 적응을 잘 할 수 있음을 의미한 다. 이에 청소년의 학교생활적응을 향상시키기 위해서는 초기 청소년들이 가정이나 학교에서 공부 및 학습관련 정보를 검색 이 용이하게 하여, 그들이 인터넷을 유익한 방향으로 사용할 수 있도록 학교와 지자체의 노력이 필요함을 제언한다.

이상과 같은 내용을 통해 초기 청소년들이 인터넷을 이용 하여 게임이나 오락을 많이 할수록 학교생활적응은 잘 하지 못하는 것으로 나타난 반면, 학습추구형 인터넷사용 증가는 학교생활적응에 긍정적인 요인임을 알 수 있었다. 이 결과는 초기 청소년의 학습과 연관 없는 컴퓨터게임이나 오락과 같 은 인터넷의 이용은 학교생활적응에 부정적 영향을 미치지만, 초기 청소년의 학교생활 즉, 공부 및 학습관련 정보 및 열람 등 학습과 연관된 이용은 학교생활적응 수준을 높인다는 것을 알 수 있게 해주었다. 청소년의 인터넷이용실태를 연구한 Jeong (2007)에 의하면, 부모의 게임시간이 많을수록 자녀도 게임에 보내는 시간이 많으며, 부모가 자료검색에 보내는 시간이 많 을수록 자녀 역시 정보검색에 보다 적극적이라고 하였다.

이에 초기 청소년의 인터넷이용을 통해 학교생활적응을 향 상시키기 위한 제언으로는 일차적으로 초기 청소년들의 인터 넷이용을 부정적인 방향으로만 볼 것이 아니라, 어떠한 유형 을 얼마나 이용하는가에 대한 교육적 방향을 제시하는 것이 중요하다고 여겨진다. 또한 초기 청소년들이 부정적인 목적으 로 인터넷을 이용하는 것을 자제시키고 학습관련 정보검색과 같은 유익한 방향으로 인터넷을 사용할 수 있도록 지자체와 학교 내에서 학부모를 대상으로 한 교육과 홍보가 우선되어야 한다. 또한 최근 대부분의 학교에서 학생 스스로 배움의 주체 가 되어 수업을 이끌어나가는 교수-학습의 일환으로 인터넷 을 활용한 수업을 접목시키고 있다. 이는 인터넷이라는 매체 가 학습을 위한 정보탐색, 자료분석, 문제해결방법을 창출할 수 있는 바람직한 교육적 대안으로서 높은 가능성을 지니고 있음을 보여주는 것이다. 따라서 이러한 가능성을 학교 또는 가정에서 실현하기 위해서는 초기 청소년의 인터넷이용과 학 교생활적응 간 심도 있는 연구가 언론학, 교육학, 심리학 및 사 회복지학 분야에서 이루어져야 한다.

본 연구는 연구결과를 토대로 논의를 하고 초기 청소년의 학교생활적응을 향상시킬 수 있는 몇 개의 제언과 함께 함의 를 제언하였다. 그럼에도 불구하고 본 연구는 다음과 같은 연 구한계를 가지며, 이에 후속연구를 제언한다. 첫째, 본 연구는 
중학교 1학년 학생만을 대상으로 하였기 때문에 전체 청소년 에 적용하는데 한계가 있으며, 또한 패널자료에서 제공하는 변수들의 한계로 인해 학교생활적응에 영향을 줄 수 있는 다 양한 변인을 포함시키지 못한 한계가 있다. 따라서 향후 연구 에서는 설문지 작업 등을 통해 전체 청소년을 대상으로 학교 생활에 영향을 줄 수 있는 다양한 변인(예, 장애요인, 다문화 사회요인, 가정 및 학교환경요인, 심리사회적 요인)을 포함하 고 성별, 부·모애착 등 그 범위를 확장하여 청소년들의 학교생 활적응 수준을 높일 수 있는 방안을 보다 실증적으로 제시하 는 노력이 필요하겠다. 또한 초기 청소년들의 비정상적인 인 터넷사용은 현대사회의 정보화시대에 초기 청소년의 학교부 적응은 물론 청소년비행에 영향을 줄 수 있는 요인으로 떠오 르고 있는 영역이다. 그러나 초기 청소년들의 부정적인 인터 넷이용 사용실태와 심리적인 문제, 적응적인 문제와 관련지어 연구된 결과가 그리 많지 않아, 다양한 영역의 변인들에 대한 심도 깊은 이론적, 경험적 논의가 이루어져야겠다.

둘째, 본 연구결과에서 정보추구형과 오락추구형 인터넷사 용이 부모애착과 학교생활적응 간을 매개하는 것으로 나타났 으며, 이러한 결과는 일부 연구를 제외하고는 대부분의 선행 연구와 일치하는 것으로 밝혀졌지만, 매개변수 투입 후 부모 애착의 영향력 감소 수준이 적고 유의도 또한 변화가 낮게 나 타났다. 특히 오락추구형은 그 변화량이 미미하게 나타났다. 이에 본 연구결과를 일반화하는데 조심스럽게 접근할 필요가 있을 것으로 보인다. 따라서 후속 연구에서는 이들 간의 관계 를 좀 더 구체화하고, 질적 연구와 같은 방법을 통해 이들 간의 영향관계를 명확히 할 필요가 있다.

셋째, 한국아동청소년패널데이터에서 정의한 측정도구의 약점으로서, 몇 개 문항만으로 한 변인을 측정한 한계가 있다. 예를 들어, 오락추구형과 학습추구형은 각 2 개의 문항만으로 구성되어 있어, 측정도구로서의 한계가 있다. 따라서 향후에 는 설문지 작업을 통해 다문항을 가진 인터넷사용유형을 정의 하여 학교생활적응에 미치는 영향관계를 실증적으로 분석할 필요가 있다. 넷째, 인터넷 사용유형을 청소년의 사용현황을 고려해서 재분류하지 못한 한계가 있다. 이는 패널데이터의 한계로서 향후에는 이를 반영한 설문작업을 통해 이를 체계적 으로 분석할 필요가 있다. 끝으로 본 연구는 횡단적 연구로 수 행되었기 때문에 학교생활적응에 대한 다양한 요인의 변화와 시간의 흐름에 따른 상태를 추정하기 어려운 점이 있다. 따라 서 후속연구에서는 종단적 연구를 통해 학교생활적응을 구성 하는 다양한 변인들과 학교생활적응 간의 선행 영향관계를 보 다 명확하게 규명할 필요가 있다.

\section{Conflict of Interest}

No potential conflict of interest relevant to this article was reported.

\section{References}

Angus, J. (2013). Parents of Children with Asperger Syndrome: Relationships between Early Attachment Experiences and Parenting Behaviors. Child Studies in Asia-Pacific Contexts, $3(1), 1-12$.

Aunola, K., Stattin, H., \& Nurmi, J. E. (2000). Parenting styles and adolescents' achievement strategies. Journal of Adolescence, 23, 205-222.

Bae, B. R. (2007). Structural equation modeling with AMOS 7: Principles and practice. Soeul, Korea: Cheong Ram press.

Bowlby, J. (1982). Attachment and loss: Attachment (2nd ed., Vol. 1.). New York, NY: Basic books.

Bretherton, I. (1999). Updating the 'internal working model' construct: Some reflections. Attachment and Human Development, 1(3), 343-358.

Byun, S. H., \& Kim, J. M. (2007). The relationships among children's, adolescents' frequency levels of playing internet games, motives for playing internet games and adaptation to school. Journal of Korean Home Management Association, 25(2), 47-58.

Cho, H. J., \& Seo, Y. S. (2010). Parental attachment, separationindividuation, adult attachment, college adjustment, and psychological distress among college freshmen. Korean Journal of Counseling and Psychology, 22(2), 385-411.

Cho, I, J. (2009). Effects of internet and cellular phone addiction on achievement of middle school students. The Journal of Learner-Centered Curriculum and Institution, 9(1), 185204.

Cho, Y. K., \& Kim, Y. S. (2009). Adolescents' media use and academic achievement: Family communication, communication competence and media competence. Korean Journal of Broadcasting and Telecommunication Studies, 23(5), 380417.

Choi, Y. J. (2005). The Influence of internalization problem and attachment to parents on the adjustment to school life in middle school students. Korean Journal of Child Studies, 26(2), 15-25.

Crockett, L. J., \& Crouter, A. C. (Eds.). (1995). Pathways through adolescence: Individual development in relation to social contexts. Hillsdale, NJ: L. Erlbaum.

Han, J. S., \& Kim, S. Y. (2006). A study on the difference in internet activities, self-control, self-regulated learning and academic achievement according to the level of internet 
addiction among middle school students. Journal of Korean Association for Educational Information and Media, 12(2), 161-188.

Hirschi, T. (1969). Causes of delinquency. Berkeley, CA: University of California Press.

Howes, C., \& Hamilton, C. E. (1993). Children's relationship with child care teachers: Stability, and concordance with parental attachment. Psycscan Developmental Psychology, 14, 15-16.

Huh, M. Y. (2000). A Development of scale on parents' rearing attitudes perceived by adolescents (Unpublished doctorial dissertation). Ewha Womans University, Seoul, Korea.

Hur, J. K., \& Kim, Y. S. (2005). The effect of security of parental attachment and social support on school-related adjustment. The Korea Journal of Women Psychology, 10(4), 483-495.

Hur, W. M. (2013). How researchers estimate indirect effect using bootstrapping: The case of simple, multiple, and double mediation. Korean Business Review, 6(3), 43-59.

Hwang, S. H. (2005). Effect on internet dependency and usage of adolescence by parents (Unpublished master's thesis). Korea University, Seoul, Korea.

Jang, Y. J., \& Kim, S. H. (2008). The impact of computer use on adolescents' social relationship and school adjustment: An analysis of Korean Youth Panel Survey data. Journal of Communication Research, 45(1), 67-96.

Jeong, J. K. (2007). Parents' socio-econoic status and adolescents' computer use pattern: Based on time diary data. Journal of Cybercommunication Academic Society, 24, 51-78.

Jeong, S. M., \& Park, Y. J. (2012). A study on the effect of the home-environment and school-environment and internet addiction on the adolescents' violence delinquency: Focused on the mediating effect of internet addiction. Journal of Korean Association of Public Safety and Criminal Justice, 48, 272-300.

Jo, E. J. (2008). The mediation effects of attachment on the relationship between adolescent's self-efficacy and school adjustment. Korean Journal of Youth Studies, 15(6), 299321.

Ju, S. J., \& Cho, S. S. (2013). The verification of mediating effects of internet addiction in relations body images and school maladjustment of youth: Focusing on the comparison of the groups according to household characteristics. Journal of Adolescent Welfare, 15(2), 33-59.

Khu, B. Y. (2007). The effects of perfectionism on the middle and high school student' school adjustment according to academic achievement. Korea Journal of Counseling, 8(3), 707-718.

Kim, C. H. (2015). The effects of mobile phone dependency perceived on school life adjustment of youth. Dongseo Media, 17, 59-96.
Kim, H. S., Lee, D. G., \& Bae, B. H. (2012). Influence of parental attachment on school adjustment as perceived by high school students: The moderating effect of adaptive defense mechanism. Korea Journal of Counseling, 13(6), 2641-2656.

Kim, H. W., \& Baik, J. S. (2011). A study on school life adjustment according to the level of internet game addiction among middle school students. Youth Facility and Environment, 9(1), 27-35.

Kim, J. H. (2013). Influence of depression and aggression of adolescents on cyber and real-world delinquency mediated by types of internet use. Journal of School Social Work, 24, 31-59.

Kim, J. H., \& Chung, I. J. (2010). The effects of poverty on school maladjustment and academic achievement mediated by parental monitoring and types of internet use. Korean Journal of Social Welfare Studies, 41(3), 29-56.

Kim, J. Y., Lee, J. H., \& Yoon, Y. W. (2011). Pathway from domestic violence to adolescents' internet game addiction - Focusing on mediating effect of parental attachment. Korean Journal of Social Welfare, 63(4), 59-82.

Kim, M. O. (2011). Mediating effects of academic and social selfefficacy on the relationships between attachment to parent and school adjustment in adolescents (Unpublished doctorial dissertation). Dankook University, Yongin, Korea.

Kim, S. M., Cho, L. L., Cheong, I, J., \& Lim, B. R. (2011). The effect of internet usage types on adolescent depression and aggression mediated by school maladjustment and academic achievement: Focusing on gender difference. Journal of School Social Work, 20, 175-195.

Kim, S. W. (2003). Effect of social support on abused children's adjustment (Unpublished master's thesis). Seoul National University, Seoul, Korea.

Kim, W. S., \& Ju, S. J. (2010). A comparative study on factors of the effects on juvenile's maladjument to their school life in urban or rural community. Korean Journal of Youth Studies, 17(11), 183-203.

Korea Internet \& Security Agency. (2014). 2014 Survey on the internet usage (Official Statistics No. 12005). Seoul, Korea: Korea Internet \& Security Agency.

Ladd, G. W., Kochenderfer, B. J., \& Coleman, C. C. (1996). Friendship quality as a predictor of young children's early school adjustment. Child Development, 67(3), 1103-1118.

Laghi F., D’Alessio, M., Pallini, S., \& Baiocco, R. (2009). Attachment representations and time perspective in adolescence. Social Indicators Research, 90(2), 181-194.

Lee, H. J. (2010). The effect of adolescent internet addiction on school adjustment - Focusing on effect of mediators, depression and impulsivity. Youth Culture Forum, 23, 143171.

Lee, M. S., \& Lee, G. M. (2006). A study of the influence of 
internet addiction on parent-adolescent communication and school adjustment. Journal of Educational Studies, 37(3), 1-23.

Lee, M. S., \& Min, H. Y. (2013). The main and interaction effects of control parenting and early adolescents' ego-resiliency on peer attachment : Focusing on the data of the Korean Children and Youth Panel Survey 2010. Journal of Korean Home Management Association, 31(6), 1-9.

Lee, S., \& Chae, M. A. (2007). Children's internet use in a family context: Influence on family relationships and parental mediation. Cyberpsychology, Behavior and Social Networking, 10(5), 640-644.

Lim, S. A. (2014). Effect of Internet use type on social-psychological problem, school adaptation, delinquency. Proceedings of The 4th Korea Child.Youth Panel Survey Conference (pp. 158170). Sejong, Korea: National Youth Policy Institution.

Lim, Y. M. (2014). Effects of child neglect, abuse by parents, children's intimacy with teachers and peer attachment on boys' and girls' psycho-social maladjustment. Korea Journal of Human Ecology, 23(3), 379-393.

Min, B. S. (1991). Effect of school life adaptation and academic selfconcept on academic achievement (Unpublished master's thesis). Hongik University, Seoul, Korea.

Ministry of Science, ICT and Future Planning, National Information Society Agency. (2015). 2014 a survey on internet addiction (Report No. NIA V-RER-14112). Seoul, Korea: Ministry of Science, ICT and Future Planning, National Information Society Agency.

Moon, E. S. (2002). Structural analysis of the social and psychological variables related to adolescents' school adjustment behaviors (Unpublished doctorial dissertation). Chungnam National University, Daejeon, Korea.

Nam, H. J. (2001). A study on the effect of parental support and monitoring on the internet Usage of Juveniles (Unpublished master's thesis). Sungkyunkwan University, Seoul, Korea.

National Youth Policy Institute. (2014). KCYPS 1-4th panel survey of 4th grade [Data file]. Sejong, Korea: National Youth Policy Institute. Retrieved from https://archive. nypi.re.kr:447/brdartcl/boardarticleList.do?brd_ id=BDIDX_k9Fd9oFi29nooCcJ7kX1I4\&srch_ctgry_ $\mathrm{idx}=$ CTIDX00043\&menu_nix=qZc474Ak

Park, E. M. (2010). Effects of adolescent's attachment to teachers, peers, mother, self-esteem, depression on school life adjustmen. Korea Journal of Play Therapy, 13(3), 75-88.

Park, H. J., Hong, N. M., \& Chung, I. J. (2014). Mediating effects of parent, teacher and peer attachment in the influence of neglect and abuse on adolescents' school adjustment:
Focusing on gender difference. Journal of Adolescent Welfare, 16(4), 319-346.

Park, J. S., \& Moon, J. W. (2006). The causal relationship of adolescent's family conflicts, self-concept, and school adjustment as health protection behavior. Korean Journal of Health Education and Promotion, 23(2), 91-107.

Park, Y. J. (2010). Study on the relationships among parents attachment, self-efficacy and school adjustment (Unpublished doctorial dissertation). Chungnam National University, Daejeon, Korea.

Preacher, K. J., \& Hayes, A. F. (2008). Asymptotic and resampling strategies for assessing and comparing indirect effects in multiple mediator models. Behavior Research Methods, 40(3), 879-891.

Richman, J. M., Bowen, G. L., \& Woolley, M. E. (2004). School failure: An eco-interactional developmental perspective. In M. W. Fraser (Ed.), Risk and resilience in childhood: An ecological perspective (2nd ed., pp. 133-160). Washington, DC: National Association of Social Workers Press.

Rosen, L. D., Cheever, N. A., \& Carrier, L. M. (2008). The association of parenting style and child age with parental limit setting and adolescent My Space behavior. Journal of Applied Developmental Psychology, 29(6), 459-471. doi: 10.1016/j.appdev.2008.07.005

Shrout, P. E., \& Bolger, N. (2002). Mediation in experimental and nonexperimental studies: New procedures and recommendations. Psychological Methods, 7(4), 422-445.

Sung, M. S., Cho, H. S., Oh, C. S., Hong, G. J., Kim, H. R., Hong, B. S., . . Park, K. H. (2009). Theory and practice of school social welfare. Seoul, Korea: Hakjisa Corp.

Williams, S. K., \& Kelly, F. D. (2005). Relationships among involvement, attachment, and behavioral problems in adolescence: Examining father's influence. The Journal of Early Adolescence, 25(2), 168-196.

\section{ORCID}

Seung Ryeol Kim http://orcid.org/0000-0002-8871-6075

Jin Yeong Song http://orcid.org/0000-0003-1006-8976

Received January 22, 2016

Revision received February 17, 2016

Accepted February 20, 2016 